\title{
PENGGABUNGAN KONSEP WEB 2.0 DAN MASHUP DALAM PEMBUATAN SITUS DINAS KEBUDAYAAN DAN PARIWISATA PROVINSI DKI JAKARTA
}

\author{
Bayu Kanigoro; Jurike V Moniaga; Rhezandra Priatama; \\ Konrad Bangun Pratomo; Dimas Eko Adityo \\ Jurusan Teknik Informatika, Fakultas Ilmu Komputer, Binus University \\ Jl. K.H. Syahdan No. 9, Palmerah, Jakarta Barat 11480. \\ bkanigoro@binus.edu
}

\begin{abstract}
This study aims to design a website of the Jakarta regional office of Culture and Tourism by combining the concept of web 2.0 and mashup. This concept combines several APIs (Application Programming Interface) into a new application. The APIs used are Facebook, Google Maps, Twitter, and Yahoo Weather. The created site applies the latest technology and advanced multimedia elements. With the combination of all elements above, a more interactive and dynamic site is succesfully obtained.
\end{abstract}

Keywords: Web 2.0, Mashup, API Facebook, API Google Maps, API Yahoo! Weather, API Twitter, Jakarta regional office of Tourism and Culture.

\begin{abstract}
ABSTRAK
Penelitian ini bertujuan untuk merancang situs Dinas Pariwisata dan Kebudayaan (BUDPAR) Provinsi DKI Jakarta dengan menggabungkan konsep web 2.0 dan mashup. Konsep ini menggabungkan beberapa API (Application Programming Interface) menjadi sebuah aplikasi baru. API yang digunakan adalah API Facebook, Google Maps, Twitter, dan Yahoo! Weather. Situs yang dibuat mengaplikasikan teknologi terbaru dan mengedepankan unsur multimedia. Dengan adanya gabungan dari semua unsur diatas, maka diperoleh sebuah situs yang lebih interaktif dan dinamis.
\end{abstract}

Kata kunci: web 2.0, Mashup, API Facebook, API Google Maps, API Yahoo! Weather, API Twitter, Dinas Pariwisata dan Kebudayaan DKI Jakarta. 


\section{PENDAHULUAN}

Dewasa ini perkembangan dunia internet semakin pesat. Internet berkembang menjadi media yang kuat untuk berkomunikasi dan memperoleh informasi secara global. Sekarang ini batasan dari internet secara global lebih besar dan beraneka ragam. Pengguna Internet terus meningkat pesat dari 16 juta orang di tahun 1995 (0,4\% penduduk dunia) menjadi 1,966 milyar pada tahun 2010 (28,7 \% penduduk dunia), dengan pertumbuhan yang tercepat datang dari luar Amerika, seperti Amerika Latin dan Asia (Global Village Online, Juni 2010). Data tersebut menunjukkan bahwa Internet dapat menjadi media promosi yang efektif dalam memajukan sektor pariwisata di Provinsi DKI Jakarta.

Dalam rangka mempromosikan sektor pariwisatanya, Pemerintah Daerah Provinsi DKI Jakarta telah membuat situs yang menyediakan informasi tentang pariwisata di Jakarta. Akan tetapi, situs tersebut hanya menyediakan informasi yang sebagian besar masih dalam bentuk teks dan tidak adanya interaksi dengan pengguna. Oleh karena itu, penulis ingin memberikan solusi yaitu membuat situs Dinas Pariwisata dan Kebudayaan Provinsi DKI Jakarta yang baru dengan menggabungkan konsep web 2.0 dan mashup yang memungkinkan pengguna saling berinteraksi dan menyediakan informasi dalam bentuk peta yang dinamis. Dengan demikian, pengguna semakin tertarik untuk berkunjung ke situs tersebut untuk melihat perkembangan apa saja yang terjadi di Jakarta.

Konsep situs yang paling banyak digunakan akhir-akhir ini adalah web 2.0. Web 2.0 sendiri biasanya diasosiasikan dengan aplikasi situs yang mempunyai fasilitas saling berbagi informasi, interoperability user-centered design, dan kolaborasi pada world wide web. Situs yang menggunakan konsep web 2.0 memungkinkan pengguna untuk melakukan sesuatu yang lebih daripada sekedar mendapatkan informasi saja. Contoh teknologi yang menggunakan konsep web 2.0 pada sisi klien adalah Asynchorous JavaScript and XML (AJAX), Adobe Flex, dan framework JavaScript lainnya seperti Yahoo UI Library, Dojo Toolkit, MooTools, dan jQuery. Dengan adanya konsep web 2.0, muncul pula konsep mashup (web application hybrid). Dalam pengembangan web, mashup adalah sebuah situs atau aplikasi yang memakai dan mengkombinasikan data, presentasi, atau fungsionalitas dari dua atau lebih sumber untuk membuat layanan yang baru.

\section{METODE}

Metode yang digunakan oleh penulis dibagi menjadi dua bagian utama, yaitu metode analisis dan metode perancangan. Metode Analisis terdiri dari studi lapangan dan studi kepustakaan. Studi lapangan mencakup survei ke kantor Dinas Pariwisata dan Kebudayaan Provinsi DKI Jakarta, benchmarking situs yang sudah ada dengan situs lain yang sejenis, wawancara dengan pihak UPT Informasi Dinas Pariwisata dan Kebudayaan Provinsi DKI Jakarta untuk melengkapi informasi yang dibutuhkan, dan menyebarkan kuesioner. Studi kepustakaan dilakukan dengan mempelajari teknologi yang digunakan dalam pembuatan situs (PHP, HTML5, CSS3, jQuery, AJAX, Google Maps, Yahoo! Weather, Twitter, dan Facebook).

Sedangkan metode perancangan dilakukan untuk perancangan sistem basis data dengan membuat ERD (Entity Relationship Diagram) dan perancangan aplikasi dengan membuat Unified Modelling Language (UML). Metode perancangan yang penulis gunakan yaitu evolutionary development approach yang didalamnya terdapat prototyping dimana kebutuhan pengguna belum diketahui dengan jelas dan nantinya dapat menambah fitur-fitur yang diinginkan oleh pengguna. 


\section{HASIL DAN PEMBAHASAN}

Aplikasi yang berhasil dibuat yaitu sebuah situs berbasis multimedia yang menggabungkan konsep web 2.0 dan mashup. Situs ini memiliki beberapa fasilitas yang mendukung proses penyampaian informasi mengenai pariwisata di Provinsi DKI Jakarta, antara lain sebagai berikut: (1) admin dapat menulis berita yang berhubungan dengan Jakarta; (2) admin dan pengguna dapat memberikan komentar terhadap berita; (3) admin dan pengguna dapat menambah tempat baru yang ada di Jakarta; (3) admin dan pengguna dapat menambahkan event mengenai tempat yang dimilikinya; (4) admin dan pengguna dapat melakukan pencarian tempat yang ada di Provinsi DKI Jakarta dan hasilnya ditampilkan dalam bentuk peta dinamis; (5) admin dan pengguna dapat melakukan pencarian berita yang telah dipublikasikan sebelumnya oleh admin; (6) admin dan pengguna dapat melakukan get direction (mendapatkan rute dari posisinya ke tempat yang ingin dituju); (7) pengguna dapat melakukan follow tempat yang menjadi favoritnya sehingga dapat memperoleh event terbaru dari tempat tersebut; (8) pengguna dapat melakukan review tempat; (9) pengguna dapat melakukan sharing berita ke akun Twitter atau Facebook-nya.

Situs Dinas Pariwisata dan Kebudayaan Provinsi DKI Jakarta yang dibuat terdiri dari 20 halaman yang diakses oleh pengguna maupun admin. Halaman yang dapat diakses oleh pengguna adalah halaman home, user panel, list news, news detail, place category, place profile, image gallery, video gallery, place search, dan news search. Halaman yang dapat diakses oleh admin adalah halaman panel admin - home, panel admin - news, panel admin - add news, panel admin - edit news, panel admin - place, panel admin - add place, panel admin - edit place, panel admin - gallery, dan panel admin - list user. Untuk mengakses halaman-halaman tersebut, admin terlebih dahulu harus melakukan login.

Halaman home adalah halaman pertama yang akan ditampilkan ketika membuka situs ini. Di dalam halaman ini terdapat lima menu utama, yaitu: home, news, place, gallery, dan contact us. Pada bagian header terdapat kolom pencarian. Pencarian dapat dilakukan dengan dua kategori, yaitu berdasarkan tempat atau berita. Konten utama halaman home terdiri dari enam bagian, yaitu: (1) featured news - menampilkan slideshow gambar dari berita terkait. Apabila diklik akan langsung menuju ke halaman berita tersebut; (2) featured place - menampilkan tempat-tempat yang diunggulkan oleh admin, seperti tempat wisata atau bangunan bersejarah; (3) currency - menampilkan kurs mata uang dengan nilai jual dan beli secara real-time yang diambil dari situs klikbca.com; (4) news - menampilkan maksimal 30 potongan berita yang diurutkan berdasarkan tanggal terkini dan disertai dengan thumbnail foto dari berita tersebut; (5) favorite - menampilkan daftar tempat yang dipisahkan sesuai kategori dan menjadi favorit pilihan pengguna berdasarkan rating tertinggi. (6) video - menampilkan sebuah video tentang pariwisata di Jakarta.

Pada bagian kanan terdapat sidebar yang terdiri dari lima bagian, yaitu: (1) event calendar, berisi jadwal event untuk bulan saat ini hingga bulan depannya. (2) weather, berisi ramalan cuaca untuk hari ini, besok, dan lusa, yang diperoleh dari API Yahoo! Weather; (3) recent activities, berisi aktivitas terbaru yang dilakukan oleh pengguna atau admin pada situs Dinas Pariwisata dan Kebudayaan Provinsi DKI Jakarta, seperti komentar, review, menambah tempat, dan event terbaru; (4) Twitter, berisi timeline dari akun Twitter milik Dinas Pariwisata dan Kebudayaan Provinsi DKI Jakarta; (5) tautan partnership, berisi gambar logo dari rekanan Dinas Pariwisata dan Kebudayaan Provinsi DKI Jakarta yang dihubungkan ke situsnya.

User panel merupakan sebuah panel untuk melakukan login pengguna dan bisa juga untuk registrasi. Pengguna juga bisa login dengan akun Facebook miliknya dengan mengklik tombol Facebook login, sehingga tidak perlu melakukan registrasi untuk mengakses situs secara keseluruhan. Apabila tombol Facebook login diklik, akan muncul jendela kecil yang mengharuskan pengguna mengisi email dan password Facebook miliknya. Setelah pengguna melakukan login, user panel berisi 
thumbnail foto, nama, dan username pengguna. Selain itu terdapat daftar tempat serta event terbaru dari tempat yang telah di-follow oleh pengguna.

Halaman list news menampilkan daftar berita yang telah dipublikasikan oleh admin. Isi berita dapat berupa hal yang berhubungan dengan lifestyle, kebudayaan di Jakarta, liputan event, atau informasi lainnya yang berhubungan dengan Jakarta. Tiap berita menampilkan thumbnail foto dan potongan isi berita. Pengguna dapat melihat isi berita mengklik judul berita atau tautan read more.

Halaman news detail menampilkan isi dari berita secara keseluruhan. Di dalamnya terdapat foto dari berita tersebut. Selain itu, pengguna juga dapat menulis komentar pada berita setelah melakukan login. Jika belum login, kolom komentar tidak dapat ditulis oleh pengguna. Hasil komentar akan ditampilkan di bawahnya berurut berdasarkan komentar terbaru.

Halaman place category menampilkan peta dinamis dan daftar tempat berdasarkan kategori yang dipilih oleh pengguna. Daftar tempat diurutkan berdasarkan rating dari yang tertinggi hingga terendah. Pada peta ditampilkan letak dan informasi dari masing-masing tempat tersebut.

Halaman place profile menampilkan foto dari tempat yang dipilih dan rating berdasarkan review pengguna. Pada halaman ini terdapat lima tab, yaitu: (1) tab info, berisi alamat, kontak, dan keterangan jelas mengenai tempat tersebut. Pengguna yang telah melakukan login dapat melakukan follow tempat tersebut untuk mendapat event-event terbaru. Jika belum login, tombol follow tidak terlihat oleh pengguna; (2) tab review, berisi daftar review tempat yang diurutkan berdasarkan review terbaru. Pengguna yang telah melakukan login dapat menulis review tempat tersebut. Penilaian rating terbagi menjadi tiga, yaitu: produk, tempat, dan servis, serta dapat memberikan komentar pada kolom yang sudah disediakan. Jika belum login, kolom untuk menulis review tidak terlihat oleh pengguna; (3) tab event, berisi daftar event tempat yang diurutkan berdasarkan event terbaru. Pengguna harus mengklik judul event untuk melihat detailnya; (4) tab map, berisi peta yang menampilkan letak tempat yang dipilih. Tab ini juga memiliki fitur untuk mencari petunjuk arah (get direction) dari tempat yang pengguna inginkan ke tempat yang dipilih serta memiliki opsi untuk memilih jenis kendaraan yang digunakan (mobil atau motor). Setelah pengguna mengklik tombol "Get Direction", jalurnya akan ditampilkan di peta dengan petunjuk jalan di bawahnya; (5) tab gallery, berisi kumpulan foto yang telah diunggah oleh pemilik tempat tersebut sehingga dapat dilihat oleh pengguna lainnya. Penulis menggunakan jQuery untuk menampilkan detail gambarnya.

Halaman image gallery menampilkan foto-foto yang berhubungan dengan Jakarta yang diunggah oleh admin. Jika salah satu thumbnail dari daftar foto tersebut diklik, akan muncul jQuery yang menampilkan gambar foto dengan ukuran sebenarnya.

Halaman video gallery menampilkan video-video yang berhubungan dengan Jakarta yang diunggah oleh admin. Jika salah satu thumbnail dari daftar video tersebut diklik, video yang diklik akan diputar di bagian atasnya.

Halaman place search menampilkan peta dinamis dan daftar tempat berdasarkan hasil pencarian pengguna. Daftar tempat diurutkan berdasarkan rating dari yang tertinggi hingga terendah. Pada peta ditampilkan letak dan informasi dari masing-masing tempat tersebut.

Halaman news search menampilkan hasil pencarian berita yang dilakukan oleh pengguna. Daftar ini menampilkan thumbnail foto dan potongan berita. Selain itu, pengguna dapat melihat berita yang akan dikunjungi dengan mengklik judul berita atau tautan read more.

Halaman admin login menampilkan form untuk melakukan login ke halaman panel admin. Halaman ini tersembunyi sehingga tidak diketahui oleh pengguna lain selain admin sehingga memiliki sisi keamanan yang baik. 
Halaman panel admin - home hanya dapat diakses oleh admin yang telah login. Halaman ini berisi pesan selamat datang kepada admin.

Halaman panel admin - news menampilkan tombol untuk menambah berita baru dan daftar berita yang telah di-post oleh admin yang diurutkan berdasarkan tanggal terbaru. Daftar ini menampilkan judul berita dan tautan untuk edit atau delete. Apabila admin mengklik tautan delete, situs akan menampilkan kotak dialog untuk konfirmasi menggunakan JavaScript.

Halaman panel admin - add news berisi form untuk menambah berita baru. Apabila checkbox "Featured" diberi tanda, akan muncul fitur untuk memasukkan gambar yang akan muncul pada bagian "Featured News" di halaman home berupa slideshow.

Halaman panel admin - edit news berisi form untuk mengubah berita yang dipilih oleh admin. Di bagian bawah terdapat daftar komentar dari berita tersebut. Komentar pengguna yang dianggap tidak layak dapat dihapus oleh admin. Halaman panel admin - place menampilkan dua bagian, yaitu: (1) daftar tempat yang telah disetujui (approve) oleh admin. Saat pertama kali dibuka, halaman ini menampilkan 5 daftar tempat terbaru. Setelah admin memilih kategori dan subkategori tempat, daftar ini menampilkan tempat-tempat yang sesuai dengan subkategori yang dipilih; (2) daftar tempat yang masih berstatus pending. Daftar ini berisi tempat yang baru di-submit oleh pengguna dan harus disetujui oleh admin agar dapat dilihat oleh pengguna lain.

Masing-masing daftar di atas menampilkan nama tempat dan tautan untuk edit atau delete. Apabila admin mengklik tautan delete, situs akan menampilkan kotak dialog untuk konfirmasi menggunakan JavaScript. Halaman panel admin - add place berisi form untuk menambah tempat baru.

Halaman panel admin - edit place berisi form untuk mengubah tempat yang dipilih oleh admin, menampilkan daftar event dan tombol untuk menambah event baru dari tempat tersebut. Daftar ini menampilkan nama event dan tautan untuk edit atau delete. Apabila admin mengklik tautan delete, situs akan menampilkan kotak dialog untuk konfirmasi menggunakan JavaScript. Halaman panel admin - gallery terdiri dari dua bagian, yaitu image dan video, yang masing-masing menampilkan daftar item yang telah di-post oleh admin dalam bentuk thumbnail dan tombol untuk menambah item baru.

Halaman panel admin - list user menampilkan data pengguna yang telah mendaftar di situs Dinas Pariwisata dan Kebudayaan Provinsi DKI Jakarta dan tautan delete. Apabila admin mengklik tautan delete, maka situs akan menampilkan kotak dialog untuk konfirmasi menggunakan JavaScript.

\section{PENUTUP}

Berdasarkan hasil analisis dan evaluasi terhadap aplikasi yang dibuat, serta uraian tentang pembangunan aplikasi situs Dinas Pariwisata dan Kebudayaan Provinsi DKI Jakarta, dapat diambil kesimpulan sebagai berikut: (1) Aplikasi situs yang telah dibuat menyediakan informasi yang lebih detail dan fasilitas pencarian sehingga mempermudah pengguna untuk mencari informasi mengenai berita atau tempat yang ada di Jakarta; (2) Aplikasi ini telah dapat menampilkan peta dinamis sehingga pengguna dapat mengetahui posisi tempat yang dicari secara akurat dan juga dapat mengetahui arah untuk menuju ke tempat tersebut; (3) Aplikasi ini bisa menjadi sarana yang baik sebagai media penghubung untuk interaksi antara pihak Dinas Pariwisata dan Kebudayaan Provinsi DKI Jakarta dengan pengunjung maupun antar pengunjung sendiri melalui fasilitas komentar berita dan rating tempat; (4) Dengan adanya situs ini, tugas admin menjadi lebih mudah karena hanya menitikberatkan pada pengontrolan informasi yang dimasukkan oleh pengguna dan pemilik tempat, bukan sebagai satu-satunya yang memasukkan data ke situs tersebut. 


\section{DAFTAR PUSTAKA}

Global Village Online. (n.d.). Internet Growth Statistics. Diakses Juni 2010, dari http://www.internetworldstats.com/emarketing.htm. 